\title{
INVESTIGATION OF MECHANICAL AND UTILITY PROPERTIES OF TWO-LAYER COTTON WOVEN FABRICS
}

\author{
Małgorzata Matusiak ${ }^{1}$, Edward Wilk ${ }^{2}$ \\ ${ }^{1}$ Institute of Architecture of Textiles, Department of Material Technologies and Textile Design, \\ Lodz University of Technology Lodz, Poland; malgorzata.matusiak@p.lodz.pl \\ ${ }^{2}$ Textile Research Institute, Lodz, Poland; ewilk@iw.lodz.pl
}

\begin{abstract}
:
The aim of presented work was to design the cotton woven fabrics which ensure thermal resistance higher than standard cotton fabrics of basic weaves. It was done in order to combine the excellent hygienic properties of cotton fibers with thermal insulation. Three variants of two-face cotton woven fabrics of different structure were designed and manufactured. Next, they were measured in the range of their basic structural, mechanical, and comfort-related properties. The results obtained were analyzed in the aspect of properties influencing the utility comfort of user wearing clothing made of the investigated fabrics.
\end{abstract}

\section{Keywords:}

woven fabrics, two-face fabrics, mechanical properties, comfort-related properties

\section{Introduction}

One of the most important functions of clothing is the protection of human being against environmental factors, especially cold. Clothing creates thermal barrier between the human and surrounding. Different textile materials and different sets of the materials are applied in thermal-insulation clothing. Traditionally, the fabrics ensuring the thermal insulation are made of wool fibers. It is due to the features of wool fibers as natural insulators. Wool insulates against heat and cold. It is comfortable in both hot and cold weather because it absorbs moisture vapor. The crimp and resilience of the wool fibers make them stand apart from each other, creating air gaps between the fibers. Unventilated air trapped in the air gaps is an excellent thermal insulator [1].

Nevertheless, the wool fibers are stiff and coarse. Due to this fact, they can cause skin irritation or even allergy. Some people, especially those with oversensitive skin, cannot wear the woolen clothing. Due to this fact, scientists are looking for other textile solutions ensuring thermal insulation. The thermal insulation of fabrics and clothing can be improved by appropriate structure of fibers and fabrics, for instance, an application of innovative thermal insulation fibers, such as hollow fibers made of synthetic polymers. The air inside the hollow fibers increases the thermal resistance of fibers and fabrics made of them (Fig. 1).

In the area of thermal insulation improvement, there are also some developments concerning yarns. The SPINAIR and LUNAFA yarns by Kurabo can be mentioned here as the examples of thermal insulating yarns. The SPINAIR is so called "hollow cotton yarn". It is made of cotton and polymer Kuralon K-Il (modified PVA), using the "focus method" of spinning developed by KURABO [2]. The modified PVA dissolves in water much better and in lower temperature than the ordinary PVA. This property is used to achieve loose structure of yarn and fabrics made of it. First, the fabrics are manufactured from the SPINAIR yarn, and next, the grey fabrics are finished according to the procedure elaborated by the yarn manufacturer. When the Kuralon K-II fibers dissolve in fabric finishing, the structure of yarn then becomes hollow-like, making the yarn and fabric made of it light, soft, and fluffy. Figure 2 presents the SPINAIR yarn worked out from the fabric before and after finishing. It can be seen that in yarn from finished fabric, there are only the cotton fibers because fibers from the polymer Kuralon K-II are dissolved.

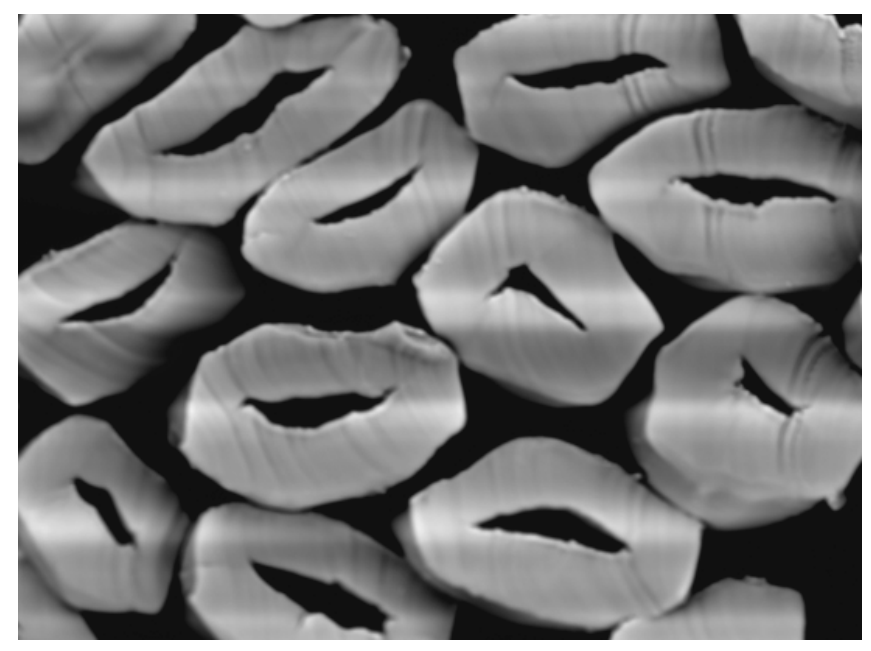

Figure 1. An example of polyamide hollow fibers [1] 


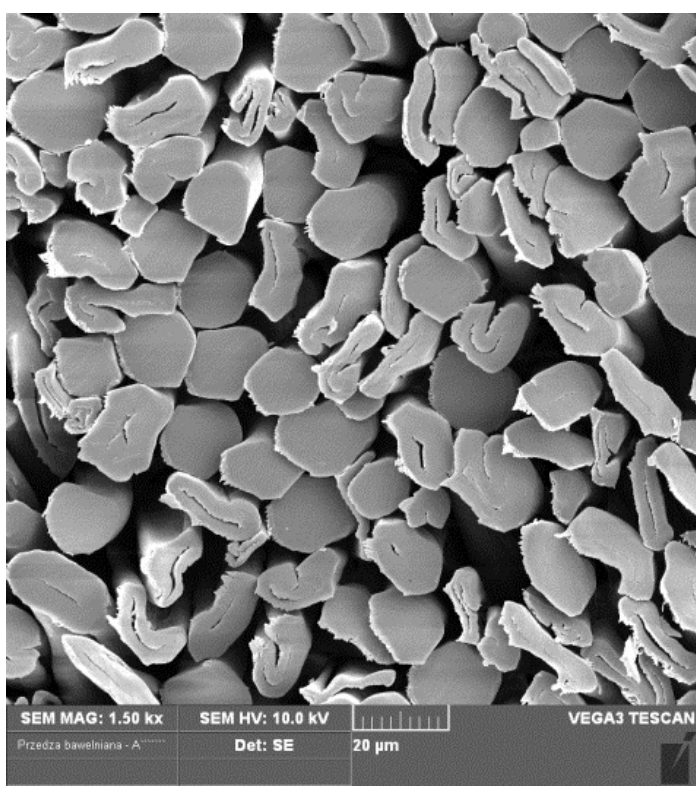

a)

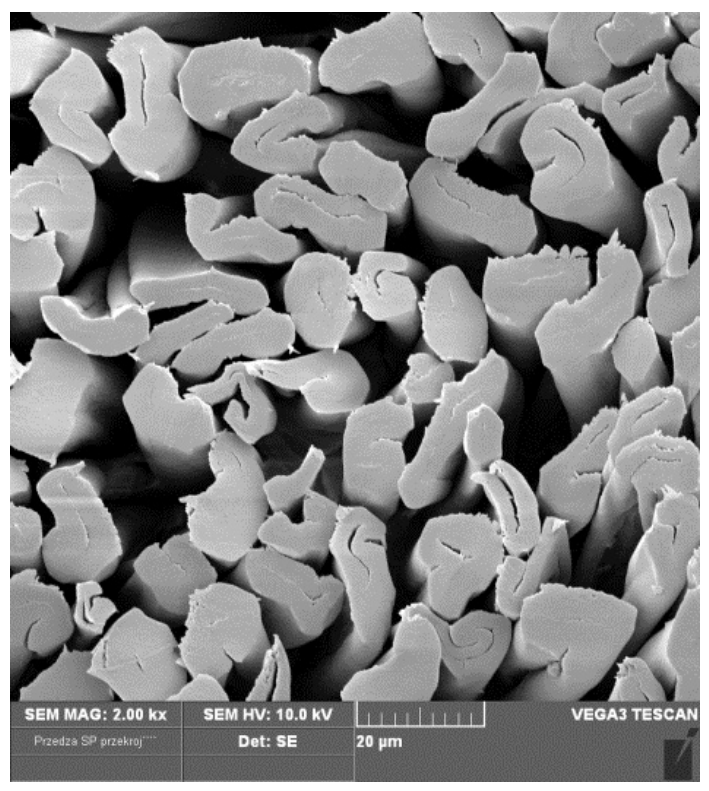

b)

Figure 2. Microscopic pictures of the SPINAIR yarn worked out from grey (a) and finished (b) fabrics

According to the declaration of the yarn manufacturer, the fabrics made of the SPINAIR yarn are lighter, more porous, and pleasant in touch in comparison to the fabrics made of conventional cotton yarns [2]. Investigations confirmed that the thermal insulation of the fabrics made of SPINAIR yarn is significantly higher than the thermal resistance of fabric made of standard cotton yarn [3].

The LUNAFA yarn (developed by Kurabo) is wool- and cottonlayered yarn (Fig. 3) It is called as "a winter cotton," because it is always warm and comfortable to the skin. The LUNAFA yarn combines the properties of wool and cotton. Because cotton fibers create the outer layer, the fabrics made of LUNAFA yarn are gentle in touch.

Thermal insulation of textile materials can be increased by designing the 3D (three-dimensional) structure of high porosity such as knitted or woven spacer fabrics. The basic common definition of $3 D$ fabric is that these types of fabrics have a third dimension in the thickness layer [4]. The 3D fabrics are also defined as thick planar sheets or shaped solid forms with multiple layers of yarns, hollow structures, and thin 3D shells [5-7].

The knitted spacer fabrics are usually two-face fabrics consisting of two layers: bottom and top connected by spacer filament. The structure of the spacer knitted fabrics ensures high porosity and big amount of air trapped between the bottom and top layer. It ensures high thermal insulation. Such kind of 3D fabrics is applied in different technical textile products such as bullet proof vests, orthosis, cycle gloves, backpacks, and mattresses [8].

There are also different woven structures that can be considered as $3 \mathrm{D}$. They can be manufactured using $2 \mathrm{D}$ or $3 \mathrm{D}$ weaving [4]. Depending on the way of manufacturing, the surface properties of the 3D woven fabrics can be different. There are $3 \mathrm{D}$ woven fabrics with the smooth surface. Some

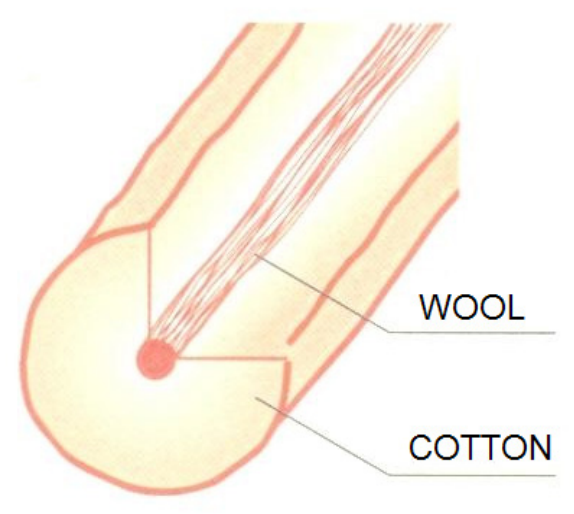

Figure 3. The idea of the LUNAFA yarn [1]

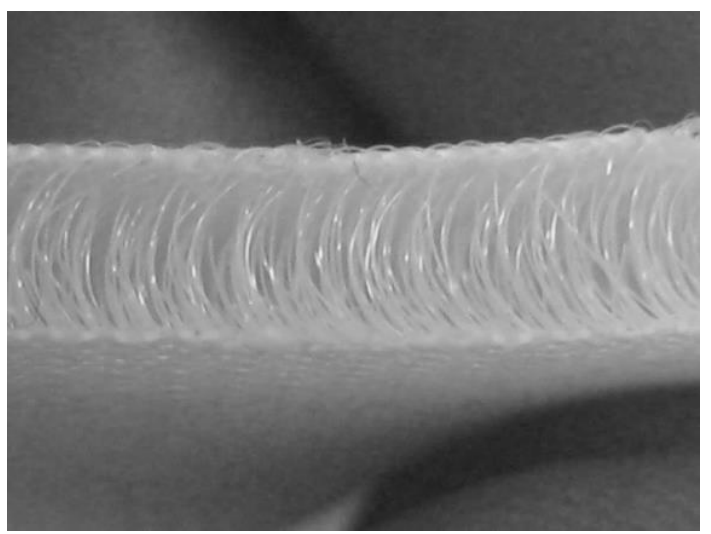

Figure 4. An example of the knitted spacer fabric [9]

kinds of the spacer fabrics or two-layer woven fabrics can be included in this group. There are also the 3D woven fabrics with the textured surface created by different elements such as plisse or pleated fabrics, terry fabrics, velvet fabrics, and seersucker fabrics (Fig. 5).

The 3D structure of the fabrics significantly influences their properties. The main factor of the 3D woven fabrics, especially the two-face ones, is their thickness. It is usually much bigger 


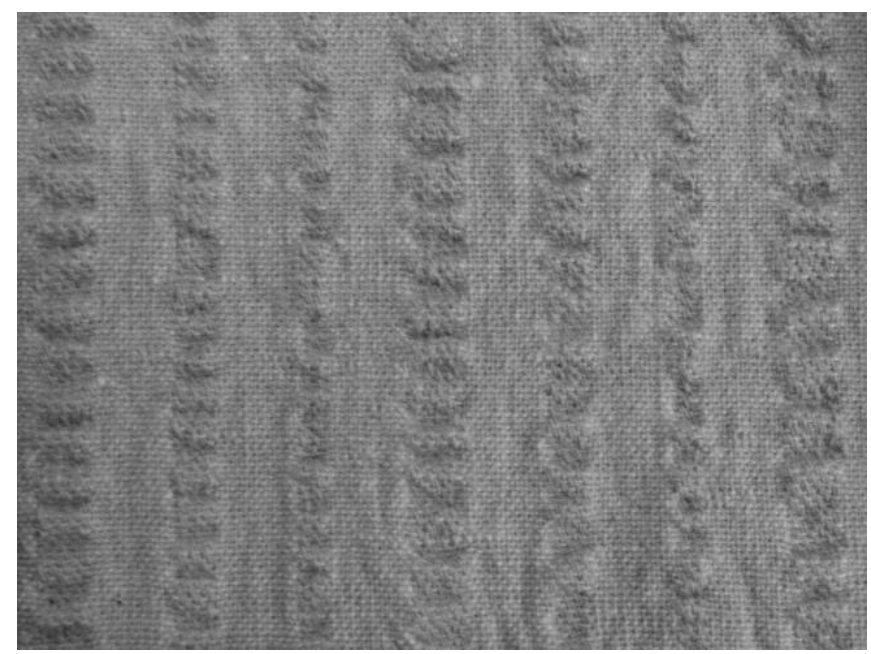

Figure 5. An example of the seersucker woven fabric

than that of the standard 2D woven fabrics. The third dimension of the 3D fabrics is crucial feature from the point of view of their thermal insulation. Due to this fact, the two-face woven fabrics are characterized by high thermal insulation. Many investigations confirmed that there is statistically significant positive correlation between the thickness and thermal resistance of the textile materials [1, 10-14]. The presence of two layers in the fabric also influences the mechanical properties of the fabrics. It results from the structure of multilayer materials and way of interlacing of yarns creating particular layers.

The topic of the 3D fabrics is extensively discussed in the literature. However, majority of works published till now concerned the 3D fabrics for technical applications, especially as preforms for textile composites [15-17, and many others]. Some articles concerning the double-layer woven fabrics for clothing applications [13, 18-21] were aimed at the investigations of the double fabrics in the range of different properties. Gupta et al. [13] investigated the sets of two singlelayer fabrics-woven and knitted-of different structure and different fiber composition. Kandhavadivu et al. [18] and Basal et al. [19] investigated the two- and three-layer sets of woven and knitted fabrics made of fibers different than cotton. Unal et al. [20] investigated the effect of different connections in doublelayered woven fabrics on comfort properties. They investigated the fabrics of different fiber composition and different weaves. The range of the investigations covered the wetting properties of fabrics.

In the literature, there are no works published till now that aimed at the two-face cotton woven fabrics of structure elaborated in the frame of presented work for clothing ensuring stilted thermal insulation.

Taking into account the irritating or even allergic action of woolen fibers as well as the problems with laundering the woolen textiles (susceptibility to pilling, long time of drying), it seems to be reasonable and justified to find other materials of good thermal insulation but more pleasant in touch and more friendly for human skin than woolen fabrics.

\section{Experimental}

The main goal of the presented work was to design the cotton woven fabrics that ensure thermal resistance higher than that of standard cotton fabrics of basic weaves. It was done in order to combine the excellent hygienic properties of cotton fibers with thermal insulation. The aim of the presented work was achieved by developing the two-face cotton woven fabrics of different structure and analyzing the properties of the developed fabrics from the point of view of the utility comfort of user wearing the clothing made of the developed fabrics. Three variants of cotton woven fabrics were designed, manufactured, and measured in the range of their chosen structural and utility properties. They were:

- two variants of two-layer fabrics,

- one variant of fabric with two layers of weft.

The results allowed analyzing the influence of the structure of the two-face woven fabrics on their properties.

\subsection{Materials and methods}

In the frame of the presented work, 3 variants of the two-face woven fabrics have been elaborated. The fabrics were made of 40-tex cotton yarn applied in warp and weft. Properties of the applied yarn are presented in Table 1.

Table 1. Properties of yarn applied in the woven fabrics

\begin{tabular}{|c|c|c|c|}
\hline Property & Method & Unit & Value \\
\hline Linear density & \multirow{2}{*}{$\begin{array}{l}\text { PN-EN ISO } \\
2060: 1997\end{array}$} & tex & 40.0 \\
\hline $\begin{array}{l}\text { Mass variation } \\
\text { coefficient }\end{array}$ & & $\%$ & 2.21 \\
\hline Tenacity & \multirow{4}{*}{$\begin{array}{l}\text { PN-EN ISO } \\
2062: 2010\end{array}$} & $\begin{array}{l}\mathrm{cN} \\
\text { tex }\end{array}$ & 9.24 \\
\hline $\begin{array}{l}\text { Breaking force } \\
\text { variation coefficient }\end{array}$ & & $\%$ & 11.6 \\
\hline Elongation at break & & $\%$ & 8.40 \\
\hline $\begin{array}{l}\text { Elongation variation } \\
\text { coefficient }\end{array}$ & & $\%$ & 7.22 \\
\hline Twist & \multirow{3}{*}{$\begin{array}{l}\text { PN-EN ISO } \\
2061: 2010\end{array}$} & rpm & 658 \\
\hline $\begin{array}{l}\text { Metrical twist } \\
\text { coefficient }\end{array}$ & & - & 131.6 \\
\hline $\begin{array}{l}\text { Twist variation } \\
\text { coefficient }\end{array}$ & & $\%$ & 2.72 \\
\hline CV Uster & \multirow{4}{*}{$\begin{array}{l}\mathrm{PN}-76 / \mathrm{P}- \\
\quad 4804\end{array}$} & $\%$ & 16.78 \\
\hline thin placs per $1000 \mathrm{~m}$ & & - & 15.2 \\
\hline $\begin{array}{l}\text { Thick places per1000 } \\
\text { m }\end{array}$ & & - & 56.0 \\
\hline Neps per 1000 m & & - & 27.2 \\
\hline
\end{tabular}


The fabrics were manufactured in the technological laboratory of the Textile Research Institute on the industrial loom MAV 206 with two beams. The nominal number of ends and picks in all variants were the same: 377 ends per $\mathrm{dm}$ and 280 picks per dm. All variants of elaborated fabrics were finished in the same way typical for cotton fabrics. Finishing process included desizing, rinsing, and drying. The basic structural and technological parameters of the elaborated two-face woven fabrics are presented in Table 2.

Figures 9-11 present the visualization of the structure of the elaborated fabrics. The visualization was prepared using WEAVE and 3-DTECG software. We can clearly see the way of connection of layers in particular fabric variants.

The fabrics were measured in the range of their mechanical and utility parameters influencing their functionality. The measurements were performed using the standardized test methods. Breaking force and elongation at break were determined using the Hounsfield tensile tester according to the standard PN-EN ISO 13934-1:2013-07. Bending stiffness of fabrics was measured by means of the cantilever stiffness tester [22]. Measurement was performed according to the standard PN-EN ISO 9073-7:2011. The elaborated fabrics were also measured in the aspect of their comfort-related properties. Air permeability was measured according to the standard

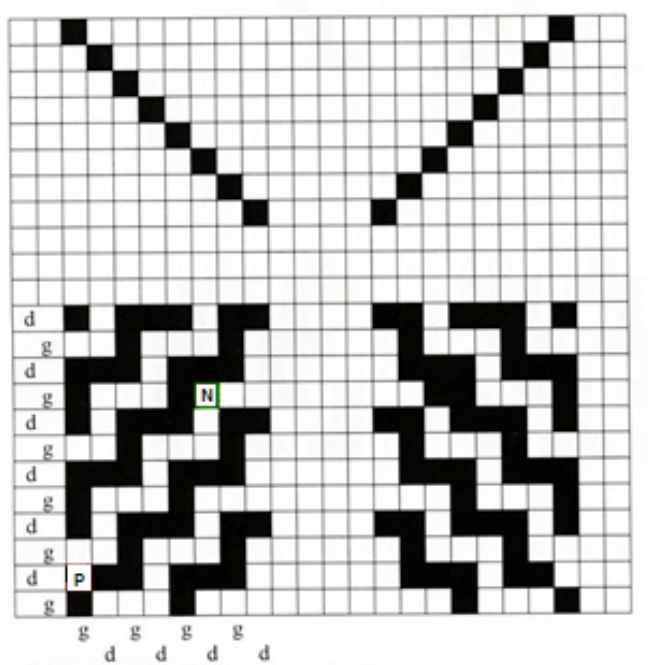

Figure 6. Weave pattern of the elaborated fabric-variant I: two-layer woven fabric of plain weaves connected by tie-up $(\mathbf{N})$ and tie-down $(\mathbf{P})$; $\mathbf{g}$, upper layer; $\mathbf{d}$, bottom layer
PN-EN ISO 9237:1998. For each variant, 10 repetitions of measurement were performed. Sweated guarded hot-plate test method was applied in the measurement of the water vapor resistance and water vapor permeability. The measurements were performed according to the standard ISO 11092. For each variant, 3 repetitions of measurement were performed.

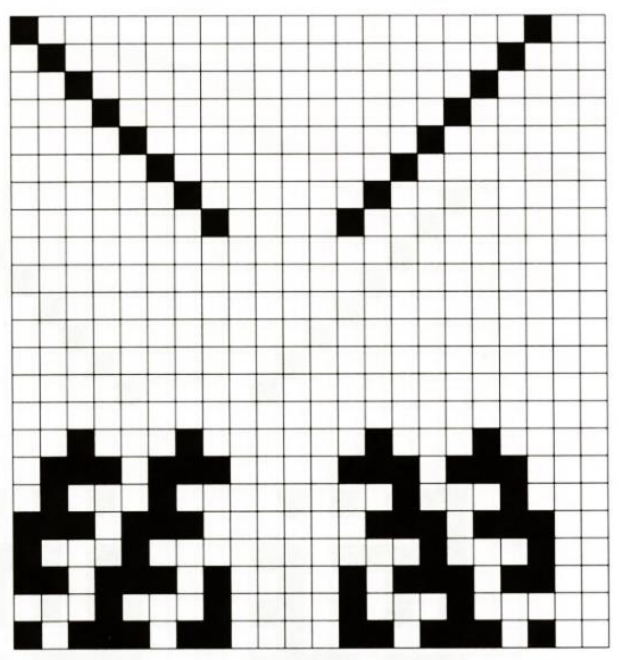

Figure 7. Weave pattern of the elaborated fabric-variant II: two-weftlayer woven fabric with twill weave $3 / 1$ and $1 / 3$

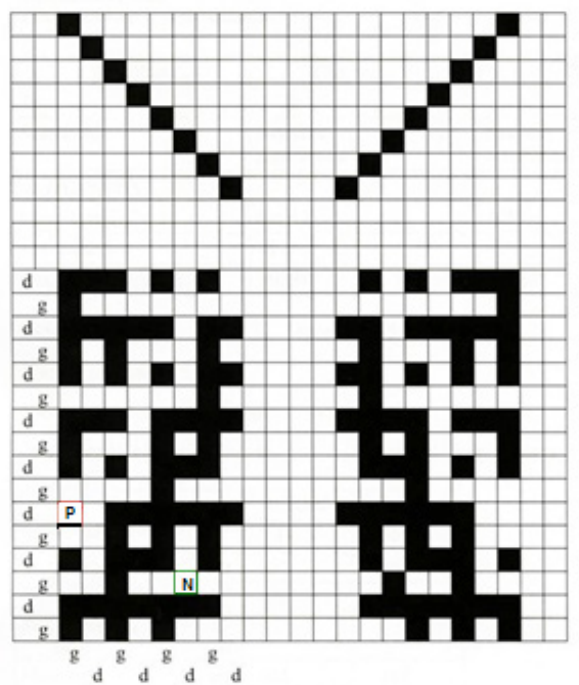

Figure 8. Weave pattern of the elaborated fabric-variant III: two-layer woven fabric of $3 / 1$ and $1 / 3$ weaves connected by tie-up $(\mathbf{N})$ and tiedown (P); g, upper layer; $\mathbf{d}$, bottom layer

Table 2. Basic structural and technological parameters of the elaborated woven fabrics

\begin{tabular}{|c|c|c|c|c|c|}
\hline Parameter & Method & Unit & Variant I & Variant II & Variant III \\
\hline $\begin{array}{l}\text { Mass per square } \\
\text { meter }\end{array}$ & PN-ISO 3801:1993 & $\mathrm{g} \mathrm{m}^{-2}$ & 288.91 & 289.15 & 281.36 \\
\hline Number of ends & \multirow{2}{*}{ PN-EN 1049-2:2000 } & $\mathrm{cm}^{-1}$ & 41.2 & 38.5 & 40.3 \\
\hline Number of picks & & $\mathrm{cm}^{-1}$ & 29.5 & 29.7 & 28.7 \\
\hline Thickness & $\begin{array}{l}\text { PN-EN ISO } \\
5084: 1999\end{array}$ & $\mathrm{~mm}$ & 0.97 & 0.99 & 1.01 \\
\hline Weave & - & - & $\begin{array}{l}\text { According to } \\
\text { Figure } 6\end{array}$ & $\begin{array}{l}\text { According to } \\
\text { Figure } 7\end{array}$ & $\begin{array}{l}\text { According to } \\
\text { Figure } 8\end{array}$ \\
\hline
\end{tabular}




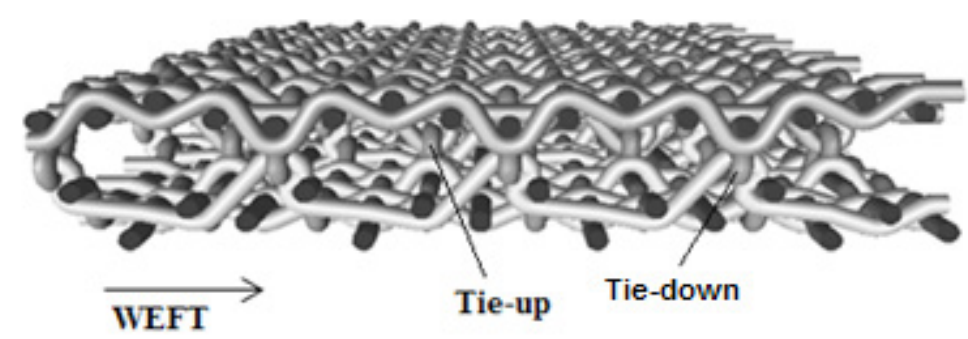

Figure 9. Simulation of the structure of the elaborated two-layer fabric-variant I

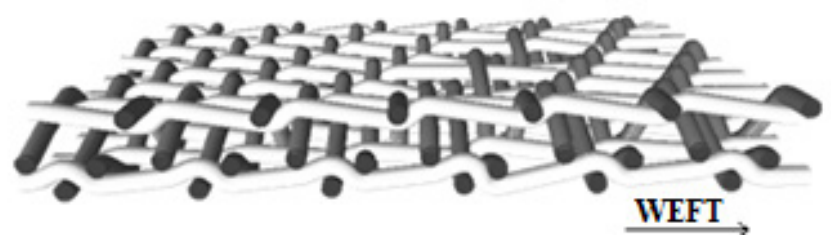

Figure 10. Simulation of the structure of the elaborated two-layer fabric-variant II

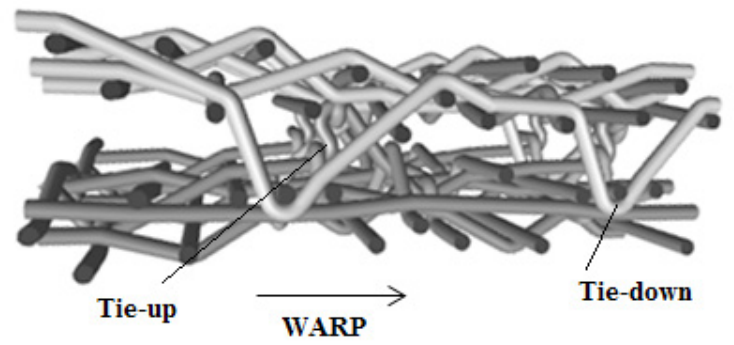

Figure 11. Simulation of the structure of the elaborated two-layer fabric-variant III

Thermal insulation properties of fabrics were measured by means of the Alambeta [1, 11, 12, 23 - 27]. The Alambeta is a computer-controlled instrument for measuring the basic static and dynamic thermal characteristics of textiles. This method belongs to the so-called "plate methods," the acting principle of which relies on the convection of heat emitted by the hot upper plate in one direction through the sample being examined to the cold bottom plate adjoined to it. The instrument directly measures the stationary heat flow density (by measuring the electric power at the known area of the plates), the temperature difference between the upper and bottom fabric surface, and the fabric's thickness.

The device calculates the real thermal resistance for all fabric configurations. In contrast, the other thermal parameters such as thermal conductivity, thermal absorption, and the thermal diffusion are calculated based on the properties measured using algorithms appropriate for homogeneous materials. The measurement was performed according to the internal standard developed in the Technical University of Liberec [24]. Three repetitions of measurement were performed for each fabric variant.

\subsection{Results and discussion}

Parameters characterizing the mechanical properties of the developed two-face fabrics are presented in Table 3.
From the point of view of the breaking force in warp direction, the fabric variants No. I and No. II are very similar. Visibly lower breaking force was stated for the variant No. III (Fig. 12). In the case of elongation at break, all investigated fabric variants differ between each other (Fig. 13). In warp direction, the highest elongation at break was stated for variant II, whereas in weft direction, it was stated for variant I. Such situation results from fabrics' weave. The highest breaking force of the fabric No. II can be explained by the fact that all warp threads have the same tension. In rest of fabric variants, $25 \%$ of warp yarns are vulnerable to increased tension and elongation because of the tie-ups and tie-downs in contrast to threads without these function.

The lowest breaking force in weft direction was stated for the variant III. It can be caused by the lowest number of picks per unit length of the fabric and not uniform tension because of connecting both the layers of the fabric only by part of the weft threads.

The fabrics differ between each other in the aspect of bending stiffness. In warp direction, the highest bending stiffness was stated for the variant No. I and the lowest for the variant No. II. In weft direction, the highest bending stiffness occurred in the sample No. II. The values of the bending stiffness can be 
Table 3. Mechanical properties of the elaborated fabrics

\begin{tabular}{|c|c|c|c|c|c|}
\hline Parameter & Method & Unit & Variant I & Variant II & Variant III \\
\hline $\begin{array}{l}\text { Breaking force } \\
\text { in warp direction } \\
\text { in weft direction }\end{array}$ & \multirow{4}{*}{$\begin{array}{c}\text { PN-EN ISO 13934- } \\
1: 2013-07\end{array}$} & $\mathrm{~N}$ & $\begin{array}{l}767 \\
574\end{array}$ & $\begin{array}{l}779 \\
578\end{array}$ & $\begin{array}{l}744 \\
450\end{array}$ \\
\hline $\begin{array}{l}\text { Breaking force } \\
\text { variation coefficient } \\
\text { in warp direction } \\
\text { in weft direction }\end{array}$ & & $\%$ & $\begin{array}{l}31.98 \\
23.7\end{array}$ & $\begin{array}{l}55.9 \\
18.8\end{array}$ & $\begin{array}{l}52.5 \\
40.1\end{array}$ \\
\hline $\begin{array}{l}\text { Elongation at break } \\
\text { in warp direction } \\
\text { in weft direction }\end{array}$ & & $\%$ & $\begin{array}{l}17.07 \\
17.03\end{array}$ & $\begin{array}{l}20.63 \\
15.54\end{array}$ & $\begin{array}{l}12.68 \\
15.32\end{array}$ \\
\hline $\begin{array}{c}\text { Elongation at break } \\
\text { variation coefficient } \\
\text { in warp direction } \\
\text { in weft direction }\end{array}$ & & $\%$ & $\begin{array}{l}0.72 \\
0.50\end{array}$ & $\begin{array}{l}0.68 \\
0.39\end{array}$ & $\begin{array}{l}0.13 \\
0.31\end{array}$ \\
\hline $\begin{array}{l}\text { Stiffness in warp } \\
\text { direction }\end{array}$ & \multirow{3}{*}{$\begin{array}{c}\text { PN-EN ISO 9073- } \\
7: 2011\end{array}$} & $\mathrm{mNm}$ & 0.055 & 0.020 & 0.042 \\
\hline $\begin{array}{l}\text { Stiffness in weft } \\
\text { direction }\end{array}$ & & $\mathrm{mNm}$ & 0.046 & 0.072 & 0.019 \\
\hline Total stiffness & & $\mathrm{mNm}$ & 0.051 & 0.038 & 0.028 \\
\hline
\end{tabular}

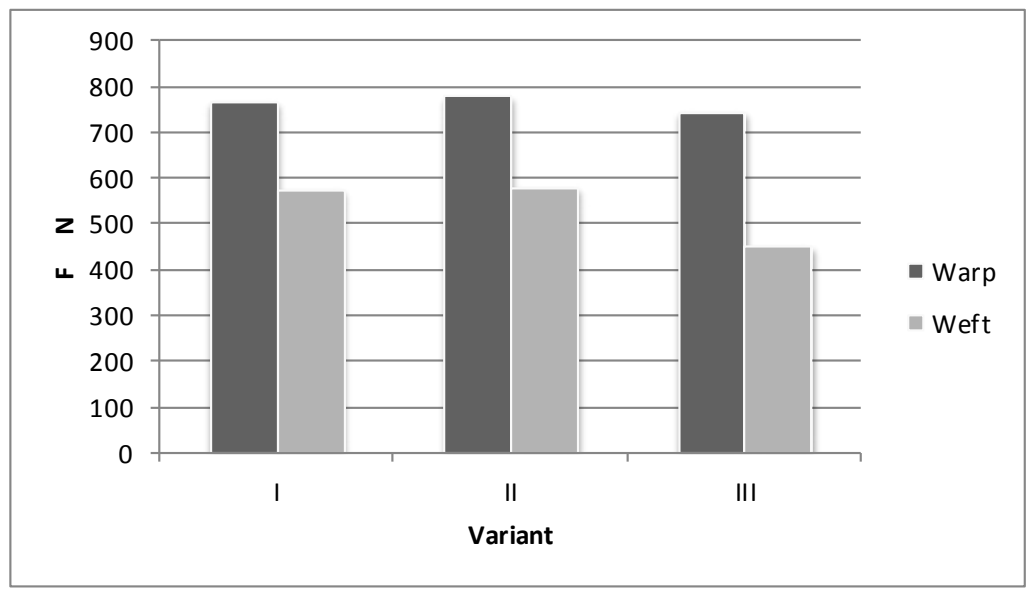

Figure 12. Breaking force of the developed two-face woven fabrics

justified by the fabrics' structure. The differences in bending stiffness in warp direction result mainly from differences in warp density. The highest value of bending stiffness in warp direction occurred for the fabric No. I, with the highest number of warp threads in centimeters, and-in opposite-the lowest occurred for fabric No. II, which is characterized by the lowest warp density (Table 4). Similar situation can be stated in weft direction. However, differences in the weft density are not so big to justify fully the differences in bending stiffness of fabrics in weft direction. In this case, the structure of the fabrics also plays significant role. Stiffness of fabrics refers to the resistance offered by a material to a force bending it [28]. Bending of the fabrics is influenced by the mobility of warp and weft yarns, which is connected with the yarn-yarn friction (Fig. 14). Higher friction leads to lower ability of the yarns to slide past each other during yarn and fabric deformation diminishes. The weft threads in fabric No. II are entwined tightly by the warp yarns of both layers (Fig. 10) what can increase the friction between yarns and, in the same way, can cause higher stiffness of fabric No. II in weft direction.

The total bending stiffness is a resultant of bending stiffness in warp and weft directions (Fig. 15). The highest total bending stiffness was stated for fabric No. I and the lowest for fabric No. III.

Table 4 presents the values of comfort-related parameters of the investigated fabrics.

It is clearly seen that the fabrics differ significantly between each other in the range of their comfort-related properties. The fabrics are manufactured from the same yarn: 40-tex 


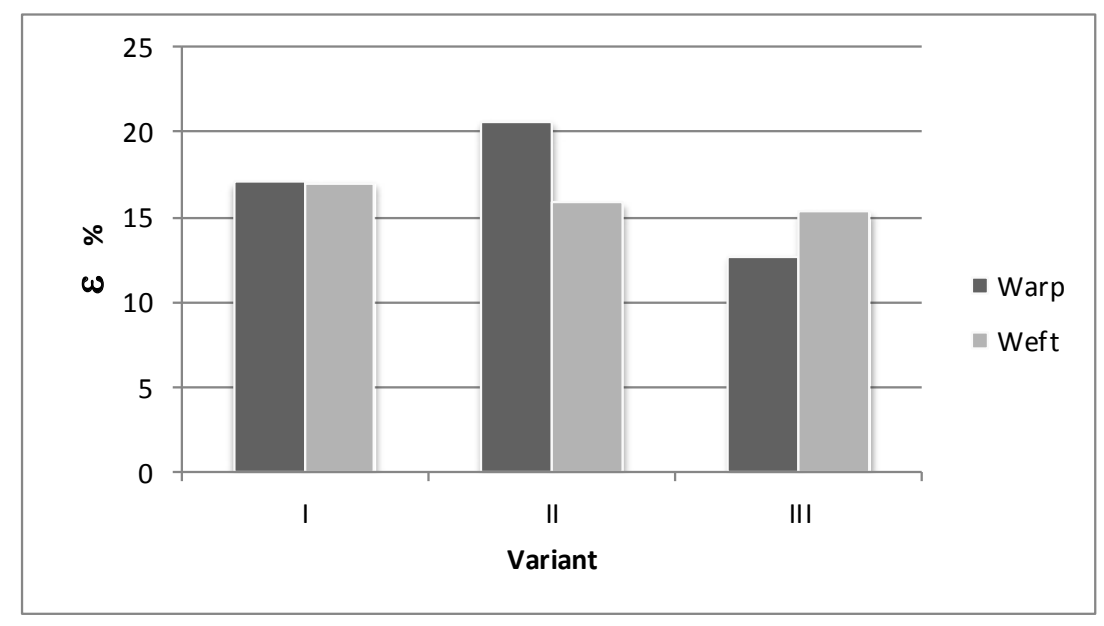

Figure 13. Elongation at break of the developed two-face woven fabrics

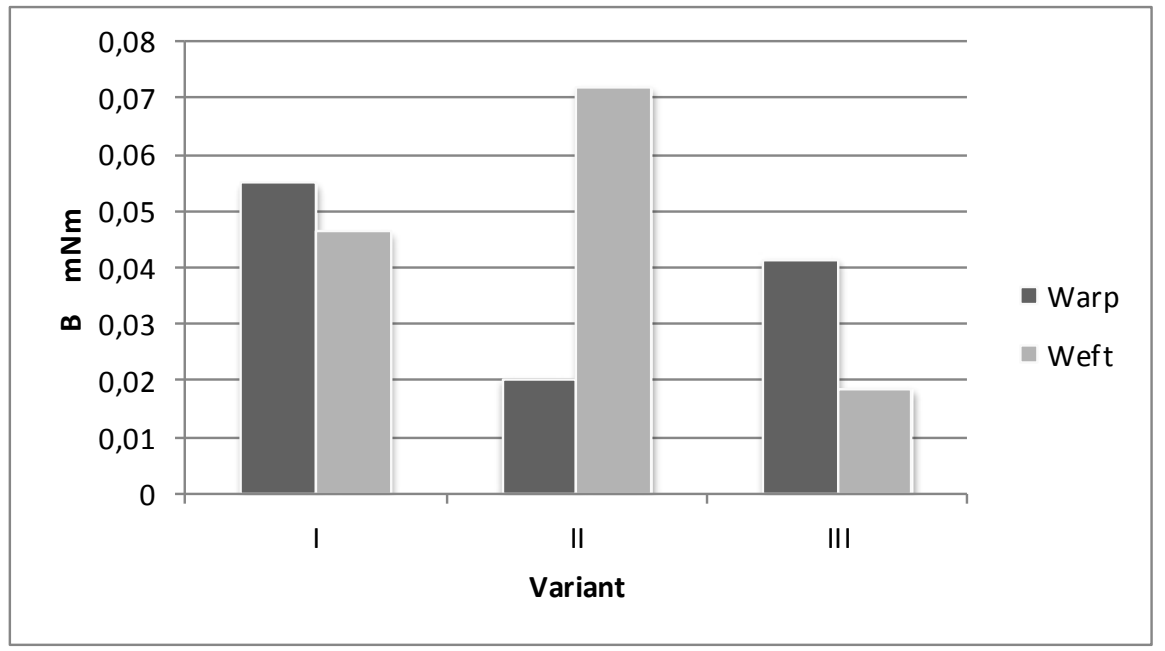

Figure 14. Bending stiffness of the developed two-face woven fabrics

Table 4.Comfort-related properties of the elaborated woven fabrics

\begin{tabular}{|c|c|c|c|c|c|}
\hline Parameter & Method & Unit & $\begin{array}{c}\text { Variant } \\
\text { I }\end{array}$ & $\begin{array}{c}\text { Variant } \\
\text { II }\end{array}$ & $\begin{array}{c}\text { Variant } \\
\text { III }\end{array}$ \\
\hline Water vapor resistance & \multirow{2}{*}{$\begin{array}{l}\text { ISO } \\
11092\end{array}$} & $\mathrm{~m}^{2} \mathrm{PaW}^{-1}$ & 4.94 & 4.23 & 4.85 \\
\hline Water vapor permeability & & $\mathrm{g}^{-} \mathrm{m}^{-2} \mathrm{~Pa}^{-1} \mathrm{~h}^{-1}$ & 0.301 & 0.351 & 0.307 \\
\hline Air permeability & ASTM D1388 & $\mathrm{mms}^{-1}$ & 381 & 463 & 672.2 \\
\hline Thermal conductivity & \multirow{3}{*}{$\begin{array}{c}\text { Internal Standard } \\
23-204-02 / 01\end{array}$} & $\mathrm{Wm}^{-1} \mathrm{~K}^{-1}$ & 0.056 & 0.057 & 0.054 \\
\hline Thermal resistance & & $\mathrm{W}^{-1} \mathrm{~K} \mathrm{~m}^{2}$ & 0.017 & 0.017 & 0.019 \\
\hline Thermal absorptivity & & $\mathrm{Wm}^{-2} \mathrm{~s}^{1 / 2} \mathrm{~K}^{-1}$ & 179.3 & 181.0 & 165.3 \\
\hline
\end{tabular}

cotton OE. The yarn was applied in warp and weft directions. Additionally, the nominal number of ends and picks in all variants were the same: 377 ends per $\mathrm{dm}$ and 280 picks per $\mathrm{dm}$. The fabrics differ between each other in the aspect of weave applied (Figs. 6-8). The fabrics are characterized by different weaves of particular layers and different ways of layer connection. Due to this fact, the behavior of the investigated fabrics in the finishing and relaxation processes was different. It caused that the final structural parameters of particular finished variants of the two-face fabrics were on different level. It concerns particularly the number of picks and ends as well as the fabric thickness. All these parameters influence the comfort-related properties of the investigated fabrics.

The fabric No. III has the highest air permeability, the fabric No. I has the lowest. It results from fabrics' weave. In the fabric No. III, the twill 3/1 weave was applied in both the layers, whereas in the fabric No. I, the plain weave was applied. The fabrics in plain weave are characterized by higher filling factor in 


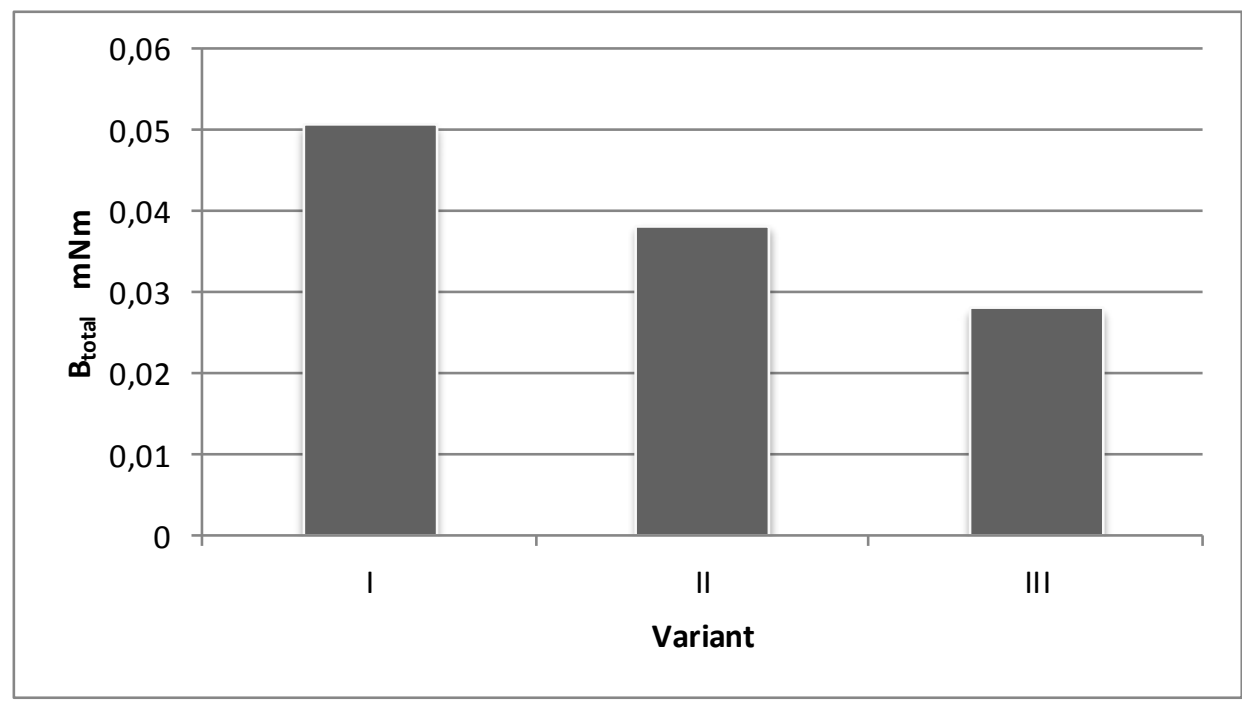

Figure 15. Total bending stiffness of the developed two-face woven fabrics

comparison with that in twill weave at the assumption that the yarn density and yarn count are the same. Fabric filling factor influences the volume porosity of fabrics, which is calculated according to the following equation [26]:

$$
P_{V}=1-\frac{A M}{h \cdot q}
$$

where

$P_{v}$ is the volume porosity,

$A M$ is the mass per square meter in $\mathrm{kg} \mathrm{m}^{-2}$,

$h$ is the fabric thickness in $\mathrm{m}$,

$q$ is the fiber density in $\mathrm{kg} \mathrm{m}^{-3}$ ( for cotton, it is 1,560).

Obtained results confirmed that there is a relationship between the air permeability and volume porosity of the investigated fabrics (Fig. 16).

The water vapor permeability of the fabrics is also different, but it is difficult to find straight relation between the fabrics and their structure. Probably, it is an effect of diversified geometry of pores between fibers, yarns, and fabric layers in connection with hygroscopicity of cotton fibers used in the fabrics.

The fabric No. III has the lowest thermal conductivity (Fig. 17). It can be explained by the fact that the fabric is characterized by the highest volume porosity [25]. It means that in comparison with the fabrics No. I and II, the sample No. III has the lowest amount of fibrous phase in its volume. It is commonly known that the heat conduction in textiles takes place mostly in fibers $[1,29-31]$. Thermal absorptivity of fabrics is a surface property $[1,11,12,23,24,26]$. It characterizes the fabrics from the point of view of warm/cool feeling while first contact with human skin. Higher value of thermal absorptivity means cooler feeling. In the case of the investigated group of fabrics, the samples No. I and II are characterized by higher value of thermal absorptivity and, in the same time, are cooler to handle than fabric No. III (Fig. 18). In the case of the fabric No. I, it can be caused by the application of plain weave in fabric layers. Previously published investigations showed that fabrics of plain weave are characterized by the highest thermal absorptivity among

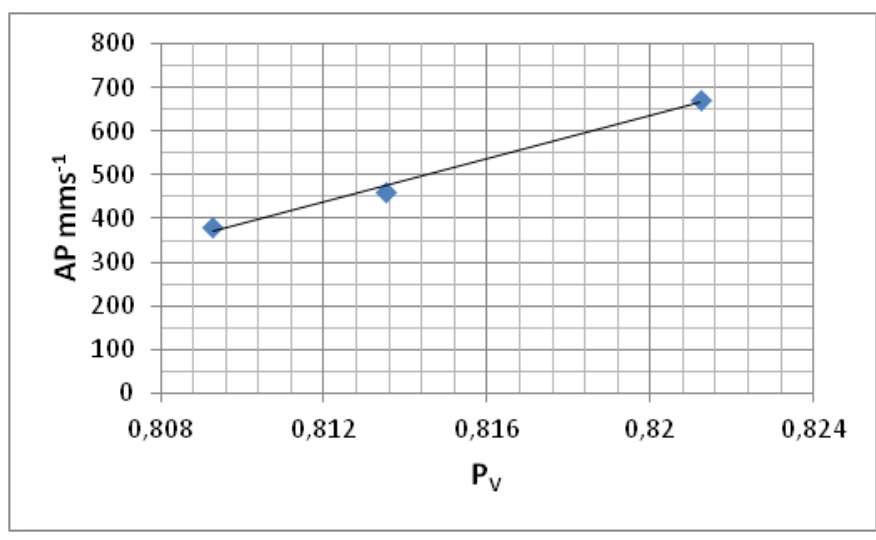

Figure 16. Air permeability versus volume porosity of the investigated two-layer fabrics

groups of woven fabrics of the same structural parameters and weave different than plain [11].

Thermal resistance of fabrics is on similar level (Fig. 19). The highest thermal resistance was stated for the fabric No. III, which is characterized by the biggest thickness. Statistical analysis using the t-Student test showed that difference between the thermal resistance of the fabric No. III and the fabric No. II is statistically significant with the probability of 0.95 . The difference between the thermal absorptivity of the fabric No. II and fabrics No. I and III is also statistically significant. In other cases, the difference between the thermal insulation properties of the investigated fabrics is statistically insignificant.

Generally, all fabrics are characterized by high thermal resistance what is the main purpose of the presented work. The thermal resistance of the elaborated two-layer cotton woven fabrics is much higher than that of typical one-layer cotton woven fabrics [1, 11, 24, 26]. For standard cotton woven fabrics of basic or derivative weaves, the thermal resistance is usually lower than $0.01 \mathrm{~W}^{-1} \mathrm{~K} \mathrm{~m}^{2}$, and very seldom; for fabrics made of coarse yarns, $60-100$ tex, it is about $0.012 \mathrm{~W}^{-1} \mathrm{~K} \mathrm{~m}^{2}$. Owing to the two-layer structure of the fabrics, it was possible to achieve the cotton fabrics of thermal insulation characteristic 


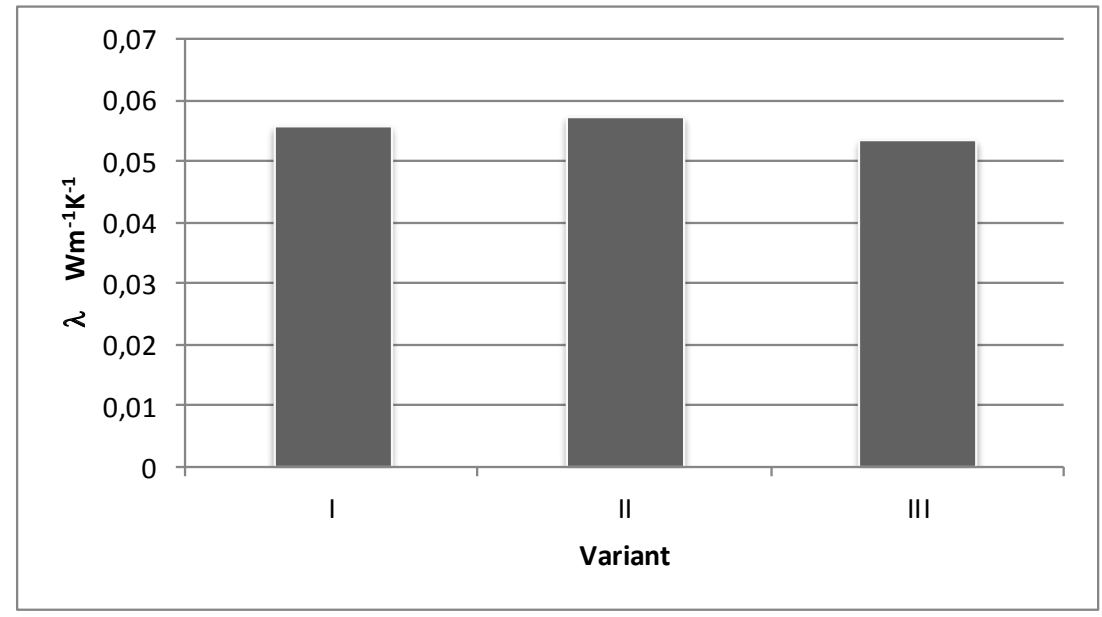

Figure 17. Thermal conductivity of the investigated two-layer fabrics

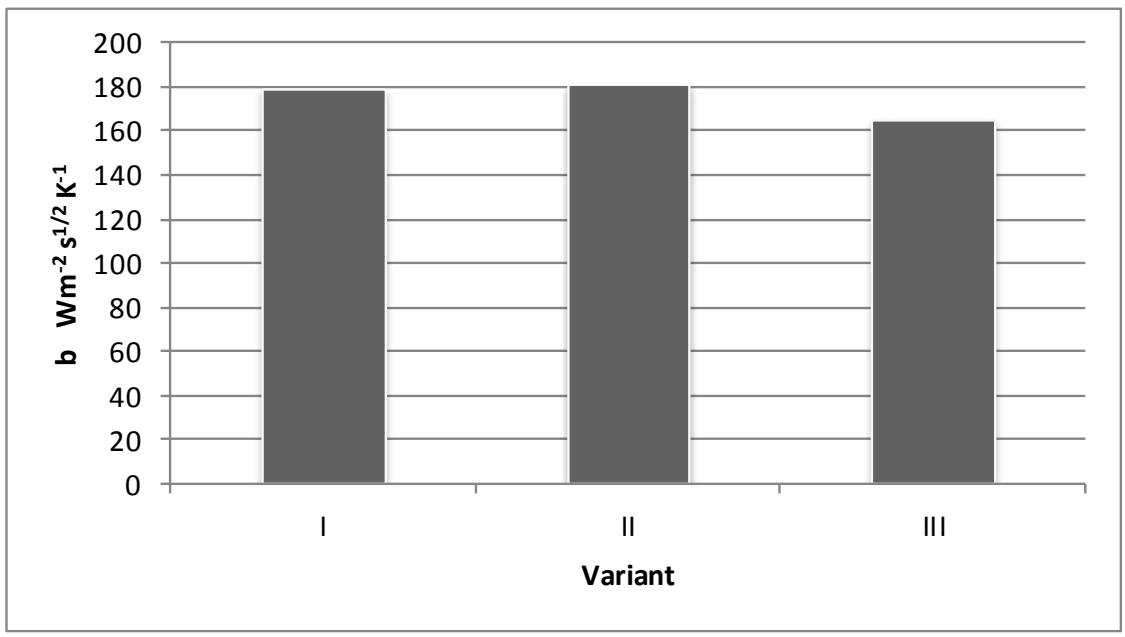

Figure 18. Thermal absorptivity of the investigated two-layer fabrics

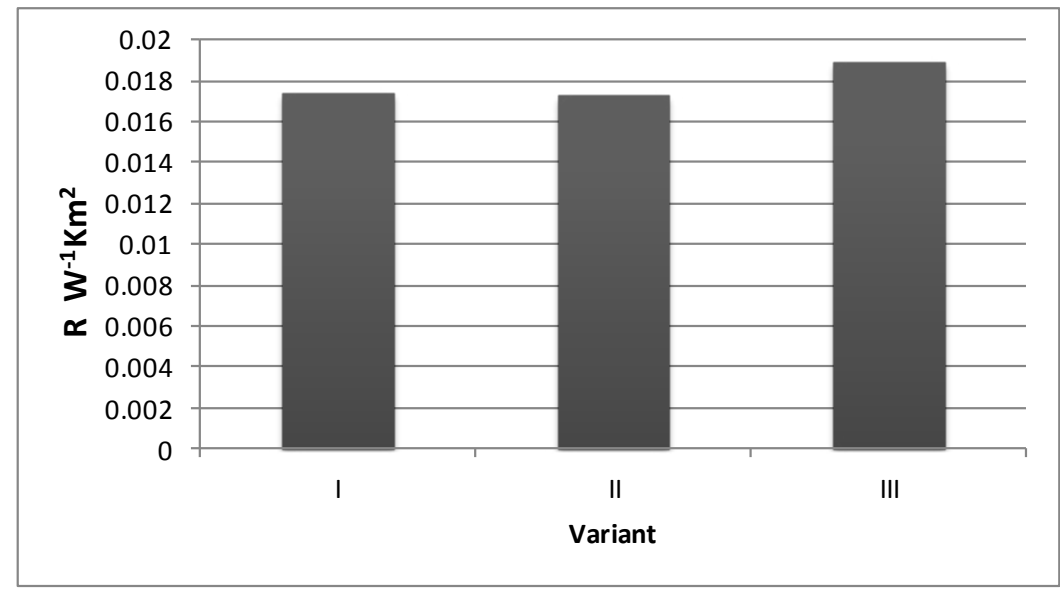

Figure 19. Thermal resistance of the investigated two-layer fabrics

for fabrics applied in winter clothing. It allows combining the soft hand and hygienic properties of cotton fabrics with high thermal insulation.

Generally, it is very difficult to discuss the results. Majority of works published till now concerned the investigations of comfort-related properties of flat woven fabrics of basic or derivative weaves $[1,11,24,26]$. Some articles concerning the double-layer woven fabrics $[13,18,21]$ were aimed at investigations of the double fabrics in the range of properties different from those investigated in the presented work. Gupta et al. [13] investigated the sets of two single-layer fabricswoven and knitted-of different structure and different fiber composition. Due to this fact, it is not sense to compare the data with the results obtained in the frame of presented work. However, the thermal resistance of the set of two adherent parallel fabrics was at the same level when compared with that of the fabrics presented in current article. 
Kandhavadivu et al. [18] and Basal et al. [19] investigated the two- and three-layer sets of woven and knitted fabrics made of fibers different from cotton. Due to this fact, their results cannot be compared with the results from presented work. However, the main goal of the investigations has been achieved. All developed variants of the two-face fabrics are characterized by thermal insulation higher than that of typical flat cotton woven fabrics. Simultaneously, the fabrics are characterized by soft hand, typical for cotton fabrics. All presented variant of fabrics can be used in clothing for users with sensitive or oversensitive skin.

\section{Conclusions}

On the basis of the performed investigations, it was stated that weave and a way of layer connection significantly influences the properties of the two-layer woven fabrics. Investigated fabric variants were manufactured from the same yarn on the same loom at the same preliminary established warp and weft density. The differences in fabric structure resulted from the applied weaves of both layers and way of layer connection. Both factors influenced the relaxation process after taking off the fabrics from loom and the behavior of the fabrics in the finishing processes. In the same way, they influenced the final structure and properties of fabrics.

In the case of all investigated fabric variants, it was possible to achieve the thermal resistance much higher than that of the typical single-layer woven fabrics. It shows the capacity of the two-layer cotton woven fabrics to be a material for clothing that protects against cold, additionally ensuring soft hand and comfortable hygienic properties.

\section{References}

[1] Matusiak M.: Thermal Insulation of Woven Fabric for Clothing. Monograph, Works of Textile Research Institute, Special Edition, Lodz 2011, ISBN 978-83-911544-7-2.

[2] http://www.kurabo.co.jp/division/yarn/english/spinair/ index.html

[3] Andrysiak J., Sikorski K., WilkE., Matusiak M., Investigation of an Innovative "Cotton Hollow" Yarn, FIBRES \& TEXTILES in Eastern Europe 2014; 22, 5(107), pp. 33-37.

[4] Unal P.G., 3D Woven Fabrics, chapter in: Woven Fabrics edited by Han-Yong Jeon, In -Tech Croatia 2012, ISBN 978-953-51-0607-4, pp. 91-120

[5] Chen X., Taylor L.W., Tsai L.J., An Overview on Fabrication of Three-Dimensional Woven Textile Preforms for Composites, Textile Research Journal 2011, Vol. 81, No.9, pp. 932-944

[6] Soden J.A., Hill J., Conventional Weaving of Shaped Preforms for Engineering Composites, Composites Part $A$ 1998, Vol.29A, pp.757-762

[7] Behera B. K., Hari P. K., Woven textile structure, Theory and applications, The Textile Institute, Woodhead Publishing Limited, Oxford (UK) 2010.

[8] Włodarczyk B., Kowalski K., Technology and Properties of Distance Five-layered Double-Weft-Knitted Fabrics with Elastomeric Threads, FIBRES \& TEXTILES in Eastern Europe 2014; 22, 1(103), pp. 68-73
[9] http://warpknits.vrtxinc.com/product/all-categories/spacerknit-fabric

[10] Socha E., Design the cold-protective clothing (in Polish), Institute of the Industrial Design, Works and materials, Item 104, Warsaw 1986.

[11] Matusiak M., Sikorski K.; Influence of the Structure of Woven Fabrics on Their Thermal Insulation Properties. FIBRES \& TEXTILES in Eastern Europe 2011, Vol. 19, No. 5 (88) pp. 46-53.

[12] Hes L., Sluka P., Uvod do komfortu textilii (in Czech), Technical University of Liberec, Liberec 2005.

[13] Gupta D, Srivastava A and Kale S. Thermal properties of single and double layer fabric assemblies. Indian Journal of Fibre \& Textile Research. 2013;38(4):387-94

[14] Zeinab S. Abdel-Rehim, M. M. Saad M. El-Shakankery and I. Hanafy, Textile Fabrics as Thermal Insulators, AUTEX Research Journal, Vol. 6, No 3, September 2006 AUTEX, pp. 148-161

[15] Hearle J. W.S., X. Chen, 3D Woven Preforms and Properties for Textile Composites, available in: < http:// iccm-central.org/Proceedings/ICCM17proceedings, on November 2017.

[16] Chen X., Wang H., Modelling and computer-aided design of $3 D$ hollow woven reinforcement for composites, The Journal of The Textile Institute 2006, 97:1, pp. 79-87,

[17] Chen X., Taylor L.W., An overview on fabrication of threedimensional woven textile preforms for composites, Textile Research Journal 2011, 81(9), pp. 932-944

[18] Kandhavadivu P., Rathinamoorthya R., Surjit R., Moisture and thermal management properties of woven and knitted tri-layer fabrics, Indian Journal of Fibre \& Textile Research 2015, Vol. 40, pp 243-249

[19] Basal G., Duran D., Mecit D., Ilgaz S., Comfort properties of double layered knitted and woven fabrics, Industria textilă 2009, 60(6), pp. 299-307 .

[20] Unal P.G., Kayseri G.O., Kanat Z.E., The Effect of Different Connections in Double Layered Woven Fabrics on Comfort Properties, Fibers and Polymers 2012, Vol.13, No.2, 258263

[21] Supure G.,Oglacioglu N., Ozdil N., Marmarali A., Moisture management and thermal absorptivity properties of doubleface knitted fabric, Textile Research Journal 2011, Vol 81, Issue 13, , pp. 1320-1330

[22] Kayseri G. Ö., G Özdil N., Mengüç G.S.Tsai L.J., Sensorial Comfort of Textile Materials, chapter in Woven Fabrics edited by Han-Yong Jeon, In -Tech Croatia 2012, , pp. 235-266.

[23] Hes, L. New achievements in the area of the objective evaluation of thermal insulation and thermal contact properties of textiles in The 3rd Asian Textile Conference, Vol. II 1995

[24] Frydrych I., Dziworska G., Bilska J., Comparative analysis of the thermal insulation properties of fabrics made of natural and man-made cellulose fibres, Fibres and Textiles in Eastern Europe, 2002, Vol. 4(39), pp. 40-44

[25] Internal Standard No. 23-204-02/01, "Measurement of the thermal properties by Alambeta device" developed in the Technical University of Liberec

[26] Militky J., Matusiak M.: Complex Characterization of Cotton Fabric Termo Physiological Comfort, 3rd International Textile, Clothing \& Design Conference, Dubrovnik 2006. 
[27] Hes L., Doleżal I., Hanzl J., „Neue Methode und Einrichtung zur objektiven Bewertung der Thermokontakten Eigenschaften textiler Flaschengebilde", Melliand Textilberichte, 679-81,9/1990.

[28] Vasile S., Ciesielska-Wróbel I.L., Van Langenhove L., Wrinkle recovery of flax fabrics with embedded superelastic shape memory alloys wires, Fibres \& Textiles in Eastern Europe 2012, Vol. 20(4), pp. 56-61.

[29] Fanger P.O., Thermal comfort, (in Polish), Kostyrko K., Kostyrko A, Arkady, Warsaw 1974.
[30] Sun Z., Pan N., Thermal conductivity and moisture diffusion in fibrous materials, chapter in: Thermal and moisture transport in fibrous materials, Edited by Pan N., Gibson P., Woodhead Publishing Limited Cambridge 2006, pp. $225-$ 270.

[31] Jun Li J., Zhang Z., Wang Y., The relationship between air gap sizes and clothing heat transfer performance, The Journal of The Textile Institute, (2013) 104:12, pp.13271336. 